\title{
Gas-Phase Polymerization of Propylene: Reaction Kinetics and Molecular Weight Distribution
}

\author{
G. B. MEIER, G. WEICKERT, W. P. M. VAN SWAAIJ \\ Department of Chemical Technology, Industrial Polymerization Processes, Process Technology Institute Twente, \\ University of Twente, P.O. Box 217, 7500 AE Enschede, The Netherlands
}

Received 10 May 2000; accepted 29 November 2000

\begin{abstract}
Gas-phase polymerizations have been executed at different temperatures, pressures, and hydrogen concentrations using $\mathrm{Me}_{2} \mathrm{Si}[\mathrm{Ind}]_{2} \mathrm{ZrCl}_{2}$ / methylaluminoxane / $\mathrm{SiO}_{2}$ (Pennsylvania Quarts) as a catalyst. The reaction rate curves have been described by a kinetic model, which takes into account the initially increasing polymerization rate. The monomer concentration in the polymer has been calculated with the FloryHuggins equation. The kinetic parameters have been determined by fitting the reaction rate curves with the model. At high temperatures, pressures, and hydrogen concentrations a runaway on particle scale may occur leading to reduced polymer yields. The molecular weight and molecular weight distribution of the polymer samples could be described by a "two-site model." At constant temperature the chain-transfer probability of sites 1 and 2 depends only on the hydrogen concentration divided by the monomer concentration. () 2001 John Wiley \& Sons, Inc. J Polym Sci A: Polym Chem 39: 500-513, 2001 Keywords: propylene polymerization; gas phase; polymerization kinetics; metallocene catalyst; molecular weight
\end{abstract}

\section{INTRODUCTION}

Despite the rapid developments in the field of metallocene catalysts, only a few articles ${ }^{1,2}$ provide kinetic data based on experiments in gaseous monomers; although, most commercial polypropylene processes are carried out in the gas phase. These processes are operated at an elevated pressure, for example, 25 bar, using heterogeneous catalysts. Resconi et al. ${ }^{3}$ showed that both molecular weight and degree of isotacticity are strongly influenced by the monomer concentration. Moreover, the kinetic behavior of a supported catalyst may differ from the homogeneous analogue. ${ }^{4}$ The lower probability of an irreversible bimolecular deactivation between active sites ${ }^{5,6}$ may, for in-

Correspondence to: G. Weickert (E-mail: g.weickert@ct. utwente.nl)

Journal of Polymer Science: Part A: Polymer Chemistry, Vol. 39, 500-513 (2001) () 2001 John Wiley \& Sons, Inc. stance, explain the general observed behavior of a lower deactivation rate in cases of supported metallocenes. There are many publications about the immobilization techniques of metallocenes onto supports, ${ }^{4,7,8}$ which may also influence the kinetic behavior.

The polymerization rate obtained with supported metallocenes clearly shows acceleration and deactivation stages in time., ${ }^{9,10}$ The nature of both the acceleration and deactivation stages has been discussed by many previous researchers. Kim et al. ${ }^{11}$ explained the acceleration stage for a highly active Ziegler-Natta catalyst with the kinetics of absorption of the co-catalyst. Bonini et al. ${ }^{10}$ excluded chemical activation processes because their metallocene catalyst was preactivated by methylaluminoxane (MAO) during the supporting procedure. They explained the acceleration by decreasing diffusion limitations of the monomer inside the catalyst particle caused by fragmentation. Their postulated particle growth 
Table I. Pore Size and Particle Size Distribution of the PQ Silica Carrier

\begin{tabular}{lccc}
\hline Characteristic & $\begin{array}{c}\text { Minimum } \\
{[\mu \mathrm{m}]}\end{array}$ & $\begin{array}{c}\text { Average } \\
{[\mu \mathrm{m}]}\end{array}$ & $\begin{array}{c}\text { Maximum } \\
{[\mu \mathrm{m}]}\end{array}$ \\
\hline Pore diameter & 0.004 & 0.2 & 5 \\
Particle size & 27 & 108 & 170 \\
\hline
\end{tabular}

model accounts for the shell-by-shell fragmentation from outside as well as a final multigrain structure of the particle. Wester et al. ${ }^{12}$ explained the initial acceleration by the slow insertion of the first monomer molecule in the alkylated catalyst. Assuming this insertion as a rate-determining step, they were able to fit experimental data obtained with $\mathrm{Me}_{2} \mathrm{Si}[\mathrm{Ind}]_{2} \mathrm{ZrCl}_{2} / \mathrm{MAO}$ as a catalyst system.

In the present article, the gas-phase polymerization of propylene with a heterogeneous metallocene catalyst is described together with the related molecular weight and molecular weight distribution of the product. Polymerizations have been executed up to 25 bar and $80^{\circ} \mathrm{C}$. The catalyst system used in this study is rac$\mathrm{Me}_{2} \mathrm{Si}[\mathrm{Ind}]_{2} \mathrm{ZrCl}_{2}$ with $\mathrm{MAO}$ as a co-catalyst. Both components are supported on Pennsylvania Quarts (PQ) silica. The kinetics are described by a model that respects both the initial acceleration as well as the deactivation of the catalyst.

\section{EXPERIMENTAL}

The experimental setup consists of a 0.5 -L jacketed Büchi reactor, a helical stirrer, an injection system for dry catalyst powder, and an evaporation vessel for monomer supply. The setup has been described in detail in a previous article. ${ }^{9}$ Polymerization reactions have been executed at constant temperature, pressure, and hydrogen concentrations. The reaction rate is calculated from the feed rate required to keep the pressure constant and measured by a mass flow controller. A special helical stirrer has been used to enforce good mixing inside the reactor. Moreover, $50 \mathrm{~g}$ of inert sodium chloride have been used for every experiment to prevent catalyst particles from sticking to each other and to the reactor wall. The catalyst is prepared under nitrogen atmosphere in a glovebox and mixed with the sodium chloride. The catalyst mixture is brought into an injection vessel, which is connected to the reactor setup.
Shortly before start-up, the catalyst mixture is injected via a valve into the evacuated reactor.

The catalyst used, rac- $\mathrm{Me}_{2} \mathrm{Si}[\mathrm{Ind}]_{2} \mathrm{ZrCl}_{2}$, supplied by Witco Co. Bergkamen (Germany), is supported on $\mathrm{PQ}$ silica with a concentration of 0.79 wt $\%$. The $\mathrm{MAO} / \mathrm{SiO}_{2}$-support used for immobilization of the metallocene contained $19.1 \mathrm{wt} \%$ of alumina. Tri-isobuthylaluminium (TIBA) has been used to increase the polymerization activity. The amount of TIBA and the precontact time has been kept constant for all experiments. Some characteristics of the silica carrier (PQ MS3040) are summarized in Table I. Note the relatively large average particle diameter $(108 \mu \mathrm{m})$. The exact polymerization procedure for the gas-phase polymerizations has been described in a previous article. ${ }^{9}$

The polypropylene samples were characterized on their molecular weight and molecular weight distribution by gel permeation chromatography (GPC). These GPC measurements were carried out at DSM Research (The Netherlands) on a Waters M150C apparatus with TSK columns at $140{ }^{\circ} \mathrm{C}$ using $1,2,4$-trichlorobenzene as solvent.

\section{Kinetic Model}

To formulate a model to describe the complex physical and chemical effects, we have chosen to describe the reaction rate by semiempirical relations. A representation of the activation, propagation, and deactivation processes is outlined in Scheme 1 . The nonactivated catalyst, $C$, is activated by a first-order relation to an activated catalyst system $C^{*}$ in

$$
\frac{d C}{d t}=-k_{i} C
$$

Here, $k_{i}=k_{i, 0} e^{-E_{\text {act }, i} / R T}$, where $k_{i}$ is the activation rate constant, and $E_{\text {act }, i}$ is the activation energy for activation.

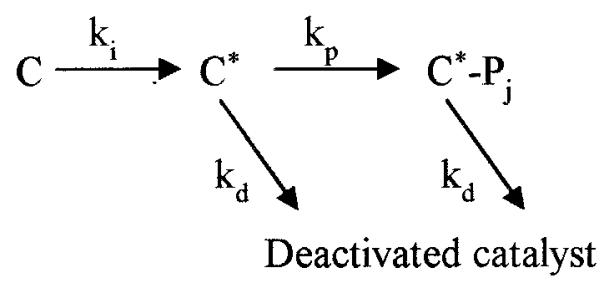

Scheme 1 
Deactivation contributes to a decreasing number of active sites, again using a first-order relation, in

$$
\frac{d C^{*}}{d t}=k_{i} C-k_{d} C^{*}
$$

Value $C^{*}$ stands for the overall number of active sites including the $C^{*}-P_{j}$ species from Scheme 1. Furthermore, it is assumed that all active sites deactivate with the same rate independently whether a chain is attached to it or not. In eq $2, k_{d}$ $=k_{d, 0} e^{-E_{\text {act }, d} / R T}$ where $k_{d}$ is the deactivation rate constant, and $E_{\text {act, } d}$ is the activation energy for deactivation.

In a previous article,${ }^{9}$ it was observed that at relatively high monomer concentrations, above 15 bars, the polymerization reaction was first order with respect to the number of active sites and the monomer concentration in the amorphous part of the polymer. In eq 3

$$
R_{p}=k_{p} C^{*} C_{m}
$$

Here, $k_{p}=k_{p, 0} e^{-E_{\text {act }, p} / R T}$, where $k_{p}$ is the propagation rate constant, and $E_{\text {act, } p}$ is the activation energy for propagation. The monomer concentration in the polymer has been calculated with the Flory-Huggins equation. The Flory-Huggins interaction parameter is based on the published experimental data. ${ }^{9}$

Integration and substitution, under isothermal conditions, of eqs 1 and 2 lead to

$$
C^{*}=C_{0} \frac{k_{i}}{k_{d}-k_{i}}\left(e^{-k_{i} t}-e^{-k_{d} t}\right)
$$

Value $C_{0}$ is the initial amount of nonactivated catalyst.

Substitution into eq 3 leads to

$$
R_{p}=k_{p} C_{m} C_{0} \frac{k_{i}}{k_{d}-k_{i}}\left(e^{-k_{i} t}-e^{-k_{d} t}\right)
$$

\section{Molecular Weight and Molecular Weight Distribution}

The molecular weight and molecular weight distribution are important parameters for the physical, mechanical, and rheological behavior of polymers. As a result of the uniform catalytically active sites of a metallocene catalyst, it is possible to control the molecular weight and molecular weight distribution. At constant temperature, pressure, and gas composition the instantaneous molecular weight distribution of a polymer synthesized with a single-site catalyst can be described by a Schulz-Flory distribution in

$$
y_{j}^{d}=j q^{2} e^{-j q}
$$

Value $y_{j}^{d}$ is the density function of the instantaneously formed molecular weight distribution. This equation depends only on the chain-termination probability $q$. This parameter is dependent on the type of catalyst and the process conditions, such as temperature, pressure, and the hydrogen concentration.

Different types of chain-transfer reactions have been observed, for example, $\beta$-hydrogen transfer to the metal and monomer, chain transfer to aluminium, chain transfer with hydrogen, and chain transfer with the monomer. Chain transfer with hydrogen is generally the most effective kind, and is often used to control the molecular weight of polypropylenes under industrial conditions. The molecular weight of a polymer sample depends on the ratio between the overall propagation rate and the total chain-transfer rates and is generally independent of the polymerization activity. Combining chain transfer and chain-growth reactions, one can derive

$$
q=\frac{k_{m} C_{m}+k_{\mathrm{H}_{2}} C_{\mathrm{H}_{2}}+k_{x}}{k_{p} C_{m}+k_{m} C_{m}+k_{\mathrm{H}_{2}} C_{\mathrm{H}_{2}}+k_{x}}
$$

where $k_{m}, k_{\mathrm{H} 2}$, and $k_{x}$ are the rate constants for chain transfer to monomer, hydrogen, and all other chain-transfer mechanisms, respectively. During polymerization, high molecular weight polymers are formed; therefore, it can be assumed that

$$
k_{p} C_{m} \gg k_{m} C_{m}+k_{\mathrm{H}_{2}} C_{\mathrm{H}_{2}}+k_{x}
$$

Furthermore, we expect chain-transfer reactions with hydrogen and monomer to be much more important than other chain-transfer mechanisms. This leads to the following equation, which corresponds to the well-known Mayo equation:

$$
q=\frac{k_{m}}{k_{p}}+\frac{k_{\mathrm{H}_{2}}}{k_{p}} \frac{C_{\mathrm{H}_{2}}}{C_{m}}
$$




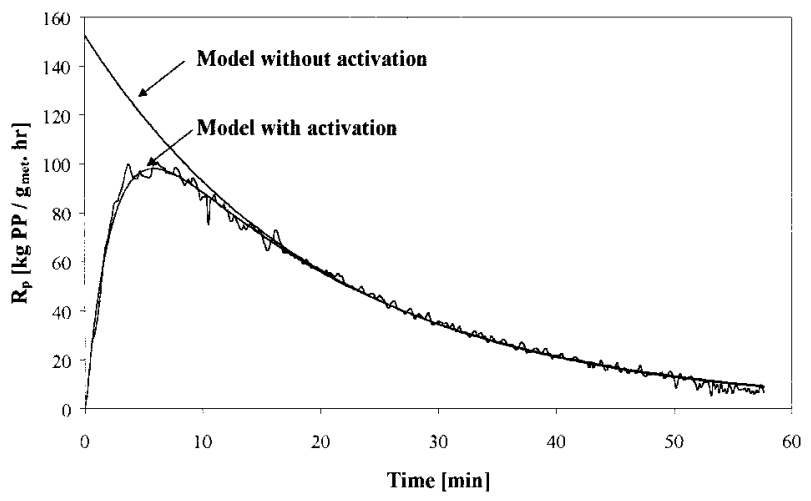

Figure 1. Fitting an experiment with the kinetic model with and without activation.

Note that $C_{\mathrm{H} 2}, C_{m}$, and temperature are constant during the experiment, which means that the instantaneous molecular weight distribution corresponds to the integral distribution obtained after the experiment. In this case, we neglect the possible change in concentration of other components, for example, MAO or TIBA. It may be possible that these components are diluted because of the production of polymer.

Data from the GPC analyses can help to calculate the chain-transfer probability in

$$
q=\frac{M_{m}}{M_{n}}=2 \frac{M_{m}}{M_{w}}
$$

where $M_{m}$ is the molecular weight of the monomer, $M_{n}$ is the number average molecular weight, and $M_{w}$ is the weight average molecular weight of the polymers (see Weickert ${ }^{13}$ ). The aforementioned equations are generally only valid for a single-site catalyst, where $M_{w} / M_{n}=2$, in case of dominating transfer reactions for chain-growth termination.

\section{RESULTS AND DISCUSSION}

The influence of temperature, pressure, and hydrogen on the polymerization kinetics has been studied by using the described kinetic model. An example of an experiment together with a fit of the model is shown in Figure 1. Fitting is done by minimizing the deviations between the experimental and model curves. A fit with the classical model without activation is also provided. It is obvious that the model without activation is not able to describe the reaction rate during the first few minutes of the experiment. After about 10 min the two different models, both using a firstorder deactivation, coincide. Note that an induction period, generally approximately $1-2 \mathrm{~min}$, is not taken into account. Therefore, $t=0$ is defined when $R_{p}$ increases from zero.

For each experiment, the measured reaction rates have been fitted to the model with activation. The values obtained for the activation constant $k_{i}$, the deactivation constant $k_{d}$, and the kinetic parameter $k_{p} C_{0}$ have been used to analyze the various process parameters in a qualitative and quantitative manner. An overall summary of

Table II. Summary of the Experiments: Temperature and Pressure Series

\begin{tabular}{|c|c|c|c|c|c|c|c|}
\hline $\begin{array}{c}T \\
\left({ }^{\circ} \mathrm{C}\right)\end{array}$ & $\begin{array}{c}p \\
\text { (bar) }\end{array}$ & $\begin{array}{c}C_{m} \\
\left(\mathrm{~kg} / \mathrm{m}^{3}\right)\end{array}$ & $\begin{array}{c}C_{\mathrm{H}_{2}} \\
\left(\mathrm{~kg} / \mathrm{m}^{3}\right)\end{array}$ & $\begin{array}{c}k_{p} C_{0} \\
\left(\mathrm{~m}^{3} / \mathrm{g}_{\text {met }} \cdot \mathrm{h}\right)\end{array}$ & $\begin{array}{c}k_{d} \\
\left(\min ^{-1}\right)\end{array}$ & $\begin{array}{c}k_{i} \\
\left(\min ^{-1}\right)\end{array}$ & $\begin{array}{c}R_{p, \max } \\
\left(\mathrm{kg} / \mathrm{g}_{\text {met }} \cdot \mathrm{h}\right)\end{array}$ \\
\hline 50 & 15 & 92.4 & 0.011 & 1.031 & 0.033 & 0.191 & 65.9 \\
\hline 60 & 15 & 67.1 & 0.011 & 1.481 & 0.038 & 0.320 & 74.6 \\
\hline 60 & 15 & 67.1 & 0.011 & 1.393 & 0.040 & 0.349 & 70.6 \\
\hline 70 & 15 & 49.8 & 0.011 & 2.563 & 0.048 & 0.440 & 98.8 \\
\hline 70 & 15 & 49.8 & 0.011 & 2.630 & 0.049 & 0.424 & 100.5 \\
\hline 75 & 15 & 44.0 & 0.011 & 2.348 & 0.046 & 0.290 & 73.1 \\
\hline 75 & 15 & 44.0 & 0.011 & 2.201 & 0.044 & 0.315 & 70.4 \\
\hline 80 & 15 & 38.2 & 0.011 & 2.149 & 0.050 & 0.311 & 57.9 \\
\hline 70 & 5.1 & 14.2 & 0.011 & 1.211 & 0.072 & 0.256 & 9.3 \\
\hline 70 & 10.1 & 30.7 & 0.011 & 2.374 & 0.070 & 0.187 & 35.5 \\
\hline 70 & 14.9 & 49.7 & 0.011 & 2.541 & 0.077 & 0.290 & 71.3 \\
\hline 70 & 17.9 & 64.9 & 0.011 & 2.766 & 0.079 & 0.300 & 100.8 \\
\hline 70 & 19.5 & 73.8 & 0.011 & 3.022 & 0.087 & 0.349 & 128.5 \\
\hline 70 & 22.6 & 95.5 & 0.011 & 2.509 & 0.099 & 0.719 & 164.6 \\
\hline 70 & 24.6 & 113.4 & 0.011 & 1.801 & 0.144 & 1.147 & 145.8 \\
\hline
\end{tabular}


Table III. Summary of the Experiments: Hydrogen Series at $70{ }^{\circ} \mathrm{C}$ and 15 bar

\begin{tabular}{|c|c|c|c|c|c|}
\hline $\begin{array}{c}C_{m} \\
\left(\mathrm{~kg} / \mathrm{m}^{3}\right)\end{array}$ & $\begin{array}{c}C_{\mathrm{H}_{2}} \\
\left(\mathrm{~kg} / \mathrm{m}^{3}\right)\end{array}$ & $\begin{array}{c}k_{p} C_{0} \\
\left(\mathrm{~m}^{3} / \mathrm{g}_{\mathrm{met}} \cdot \mathrm{h}\right)\end{array}$ & $\begin{array}{c}k_{d} \\
\left(\min ^{-1}\right)\end{array}$ & $\begin{array}{c}k_{i} \\
\left(\min ^{-1}\right)\end{array}$ & $\begin{array}{c}R_{p, \max } \\
\left(\mathrm{kg} / \mathrm{g}_{\text {met }} \cdot \mathrm{h}\right)\end{array}$ \\
\hline 50.7 & 0 & 0.520 & 0.040 & 0.146 & 16.2 \\
\hline 50.7 & 0 & 0.600 & 0.028 & 0.210 & 22.3 \\
\hline 50.5 & 0.0034 & 1.204 & 0.056 & 0.362 & 43.3 \\
\hline 50.4 & 0.0037 & 1.131 & 0.060 & 0.348 & 48.2 \\
\hline 50.3 & 0.0053 & 1.384 & 0.053 & 0.305 & 46.9 \\
\hline 50.3 & 0.0054 & 1.371 & 0.067 & 0.355 & 65.1 \\
\hline 50.0 & 0.0109 & 1.760 & 0.061 & 0.477 & 60.4 \\
\hline 50.0 & 0.0107 & 1.752 & 0.061 & 0.345 & 69.7 \\
\hline 49.9 & 0.0116 & 1.908 & 0.067 & 0.495 & 88.0 \\
\hline 49.3 & 0.0214 & 2.276 & 0.069 & 0.744 & 103.3 \\
\hline 49.2 & 0.0322 & 2.551 & 0.080 & 1.218 & 87.7 \\
\hline 49.0 & 0.0324 & 2.136 & 0.069 & 1.167 & 104.4 \\
\hline 48.6 & 0.0443 & 2.534 & 0.064 & 1.200 & 120.1 \\
\hline 46.2 & 0.0684 & 3.175 & 0.074 & 1.544 & 126.1 \\
\hline
\end{tabular}

the experiments, presenting the process conditions and determined kinetic parameters, is displayed in Tables II-IV.

\section{Influence of Temperature}

The influence of temperature has been investigated at 15 bar at temperatures between 50 and $80{ }^{\circ} \mathrm{C}$. The hydrogen concentration has been kept constant at $0.011 \mathrm{~kg} / \mathrm{m}^{3}$, which is about $1 \mathrm{vol} \%$. The Arrhenius plot for propagation is provided, showing a linear behavior for temperatures between 50 and $70{ }^{\circ} \mathrm{C}$, in Figure 2. The experiments at 75 and $80{ }^{\circ} \mathrm{C}$ showed a considerable lower activity. The Arrhenius plots for deactivation and activation are also given, respectively, showing again a more or less linear relation between 50 and $70^{\circ} \mathrm{C}$ as well as a deviating behavior above 70 ${ }^{\circ} \mathrm{C}$ (Figs. 3 and 4). The determined kinetic param-

Table IV. Summary of the Experiments: Temperature Series without Hydrogen at 15 bar

\begin{tabular}{ccccc}
\hline $\begin{array}{c}T \\
\left({ }^{\circ} \mathrm{C}\right)\end{array}$ & $\begin{array}{c}C_{m} \\
\left(\mathrm{~kg} / \mathrm{m}^{3}\right)\end{array}$ & $\begin{array}{c}k_{p} C_{0} \\
\left(\mathrm{~m}^{3} / \mathrm{g}_{\text {met }} \cdot \mathrm{h}\right)\end{array}$ & $\begin{array}{c}k_{d} \\
\left(\mathrm{~min}^{-1}\right)\end{array}$ & $\begin{array}{c}k_{i} \\
\left(\mathrm{~min}^{-1}\right)\end{array}$ \\
\hline 50 & 91.8 & 0.165 & 0.050 & 0.428 \\
50 & 91.8 & 0.152 & 0.042 & 0.405 \\
60 & 66.9 & 0.311 & 0.035 & 0.440 \\
60 & 66.9 & 0.366 & 0.043 & 0.588 \\
70 & 50.6 & 0.600 & 0.028 & 0.210 \\
70 & 50.6 & 0.520 & 0.040 & 0.146 \\
80 & 38.2 & 1.305 & 0.069 & 0.288 \\
80 & 38.2 & 1.077 & 0.065 & 0.325 \\
\hline
\end{tabular}

eters are summarized in Table V. The activation energy for propagation, $43.9 \mathrm{~kJ} / \mathrm{mol}$, is quite close to the value found previously, ${ }^{9} 48.0 \mathrm{~kJ} / \mathrm{mol}$, where the same metallocene on a different support was used for gas-phase polymerizations at 10 bar pressure. Note that in our previous work, the activation energy was determined based on a model without activation.

The possibility of particle overheating at the start of the reaction, where the highly concentrated catalyst particles still have a small external surface, has been the subject of many discussions in the literature. ${ }^{14-16}$ The elevated particle temperature may lead to chemical reactions among the various catalyst components, and especially the stability of MAO at higher temperatures is questionable. The particle temperature is dependent on the heat-transfer coefficient, the heat-transfer area, and the difference between bulk and particle temperature. The internal temperature gradients are generally small. Samson et al. $^{2}$ found, for both gas- and liquid-phase polymerization with a Ziegler-Natta catalyst, rapid catalyst deactivation above a certain temperature. The absolute polymerization rate, per gram of catalyst (including support), are in the same order of magnitude as observed in the present article: $1-3 \mathrm{~kg} \mathrm{PP} /\left(\mathrm{g}_{\text {cat }} \dot{\mathrm{h}}\right)$.

Prepolymerizations were executed by Samson et al. ${ }^{2}$ to prevent a thermal runaway on particle scale; prepolymerization may help to prevent a thermal runaway on particle scale. Because the reaction rate is much lower in the prepolymerization step compared to the main polymerization, 


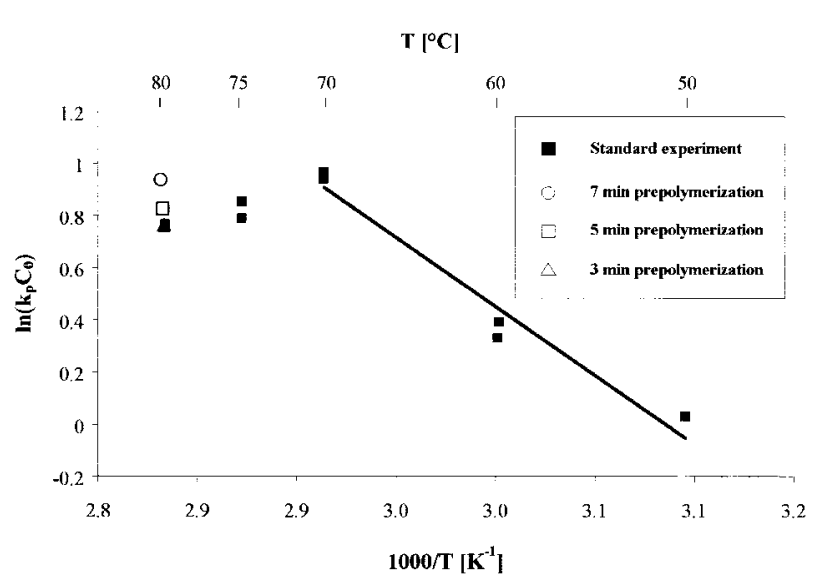

Figure 2. Arrhenius plot for propagation (open dots represent the prepolymerization experiments).

particles have time to grow in a controlled way to a size where the external surface is large enough to remove all the reaction heat. The observed reaction rates by Samson et al. were significantly higher than without prepolymerization. The prepolymerizations were carried out at low temperatures in either liquid propylene or pentane slurry. To test the same procedure for a heterogeneous metallocene catalyst, prepolymerizations have been executed in gaseous propylene at $40^{\circ} \mathrm{C}$ and 5 bar monomer pressure. The prepolymerization time was varied between 3 and $7 \mathrm{~min}$; afterward, the temperature and pressure were raised to $80{ }^{\circ} \mathrm{C}$ and 15 bar, respectively. As can be seen in Figure 2, prepolymerization of the catalyst results in a higher reaction rate for the main polymerization reaction. However, a large deviation with the Arrhenius plot still exists, even for a prepolymerization time of $7 \mathrm{~min}$. Obviously, there are more effects to consider than only initial particle overheating.

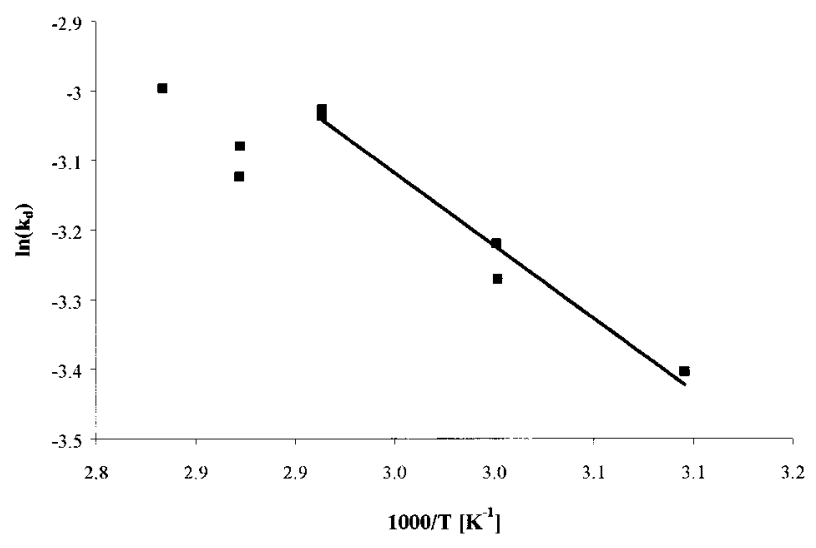

Figure 3. Arrhenius plot for deactivation.

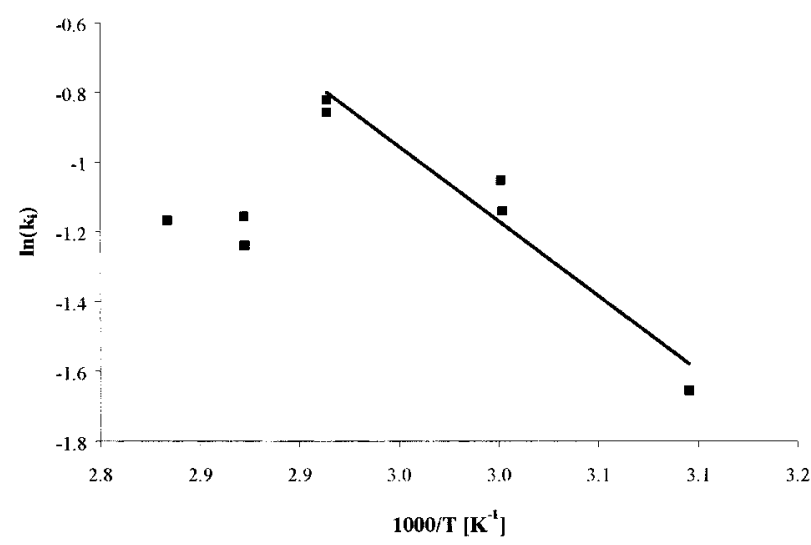

Figure 4. Arrhenius plot for activation.

In the next series, the influence of temperature in the absence of hydrogen was investigated at 15 bar as well as temperatures between 50 and 80 ${ }^{\circ} \mathrm{C}$. The Arrhenius plot is given, showing a linear behavior in contrast to the temperature series with hydrogen (Fig. 5). No discrepancy was found at temperatures above $70{ }^{\circ} \mathrm{C}$. Because of the low reaction rate in absence of hydrogen, the chance of a runaway is small, even at $80^{\circ} \mathrm{C}$. The activation energy for propagation derived for this case is $58.9 \mathrm{~kJ} / \mathrm{mol}$. This value is higher compared to the value obtained in the presence of hydrogen (43.9 $\mathrm{kJ} / \mathrm{mol}$ ). A possible explanation for this may be that the catalyst applied is not completely single site, and certain sites have different sensitivity towards hydrogen. Further discussion on a possible non-single-site behavior of the heterogeneous metallocene catalyst follows.

\section{Influence of Pressure}

The influence of pressure has been investigated in the range between 5 and 25 bar as well as at 70

Table V. Summary of the Determined Kinetic Parameters

\begin{tabular}{lcl}
\hline Model Parameters & Value & $\begin{array}{c}\text { Unit of } \\
\text { Measurement }\end{array}$ \\
\hline$E_{\text {act }, p}$ & 43.9 & $\mathrm{kJJ} / \mathrm{mol}$ \\
$E_{\text {act }, d}$ & 17.4 & $\mathrm{~kJ} / \mathrm{mol}$ \\
$E_{\text {act, } i}$ & 35.6 & $\mathrm{~kJ} / \mathrm{mol}$ \\
$k_{p 0} C_{0}$ & $1.20 \cdot 10^{7}$ & $\mathrm{~m}^{3} / \mathrm{g}_{\text {met }} \cdot \mathrm{h}$ \\
$k_{d 0}$ & 21.3 & $\mathrm{~min}^{-1}$ \\
$k_{i 0}$ & $1.19 \cdot 10^{5}$ & $\mathrm{~min}^{-1}$ \\
Validity range & $50-70$ & ${ }^{\circ} \mathrm{C}$ \\
\hline
\end{tabular}




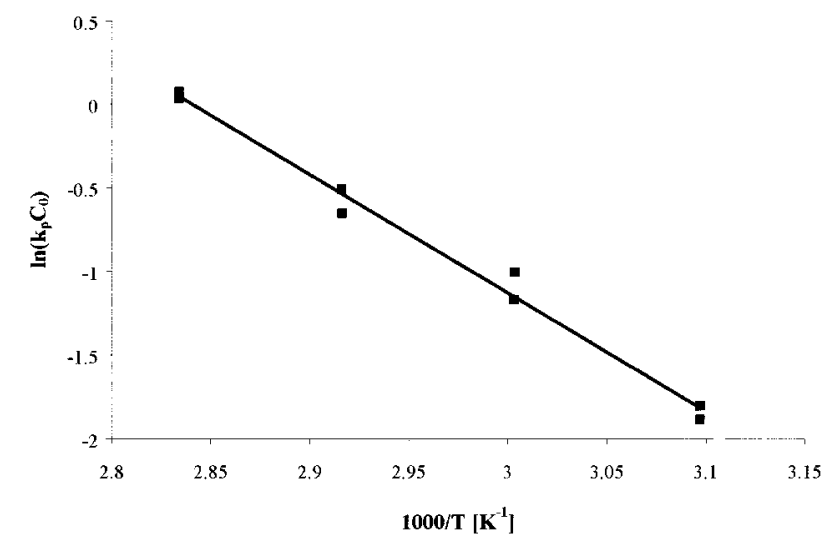

Figure 5. Arrhenius plot for propagation in the absence of hydrogen.

${ }^{\circ} \mathrm{C}$. The hydrogen concentration has been kept constant at $0.011 \mathrm{~kg} / \mathrm{m}^{3}$, which is the same value as used for the temperature series. The influence of monomer concentration on the kinetic parameter $k_{p} C_{0} C_{m}$ is shown in Figure 6. The monomer concentration $C_{m}$ is based on the monomer concentration in the amorphous part of the polymer. For a first-order reaction, a linear relation is expected with an intercept equal to zero. As can be seen from Figure 6, a linear relation is obtained for pressures between 5.1 and 19.5 bar, whereas deviations occur at higher pressures (22.6 and 24.6 bar). Moreover, the intercept is not equal to zero, indicating a higher reaction order at low monomer concentrations. This is in agreement with the literature. ${ }^{9,17}$

The deviations observed at high pressures can be explained in a similar way as was done for the temperature series. At high polymerization rates,

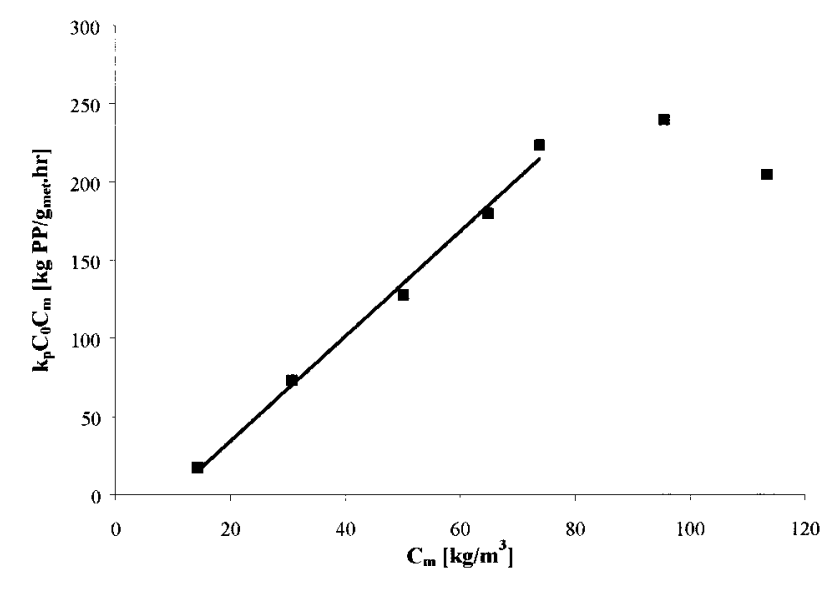

Figure 6. Influence of monomer concentration on $k_{p} C_{0} C_{m}$.

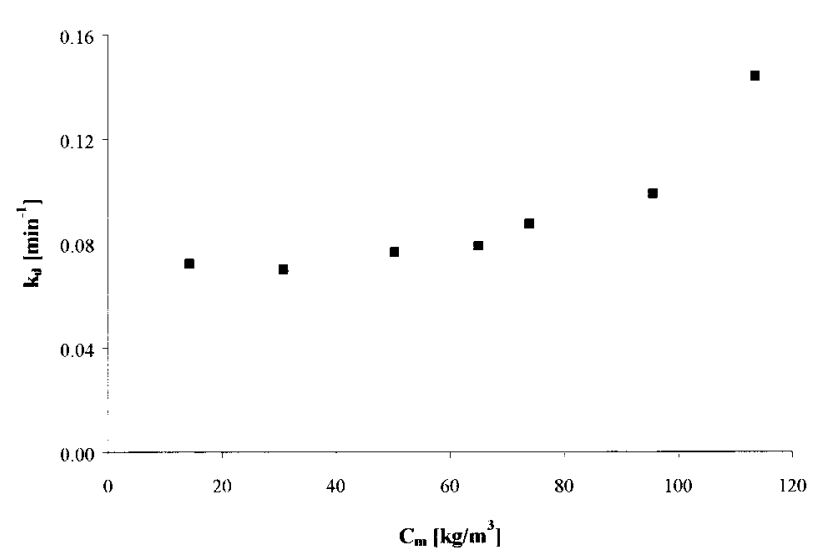

Figure 7. Influence of monomer concentration on $k_{d}$.

that is, high monomer concentrations or bulk temperatures, the particle temperature may be substantial higher than the bulk temperature, which may lead to chemical deactivation reactions. The maximum polymerization activity observed for the case of particle excess temperature behavior should be in the same order of magnitude for the pressure and temperature series because in those cases, the actual particle temperature can be expected to be similar. The previously described behavior is confirmed by the determined $R_{p, \text { max }}$ values presented in Table II.

The deviations observed at high pressures have not been found in the literature, ${ }^{9}$ where the same catalyst was used but on a different silica support. The average particle size of the support used in the present article is about a factor of two (108 vs $51 \mu \mathrm{m}$ ) larger than used in previous work. Therefore, the volume-to-surface area ratio of the catalyst used in this work is about a factor of two higher, whereas the activity per gram of catalyst is about the same. This makes heat removal from the larger particle more difficult.

The influence of the monomer concentration on the deactivation and activation constant is given in Figures 7 and 8. As can be seen, the two constants are hardly affected by the monomer concentration, except for the two experiments at 22.6 and 24.6 bar. The values for $k_{d}$ and $k_{i}$ for these two experiments are higher compared to the values at low concentration. This is in contradiction to the behavior observed in the temperature series.

\section{Influence of Hydrogen}

The influence of hydrogen has been investigated at 15 bar and $70{ }^{\circ} \mathrm{C}$ between 0 and $0.068 \mathrm{~kg} / \mathrm{m}^{3}$ 


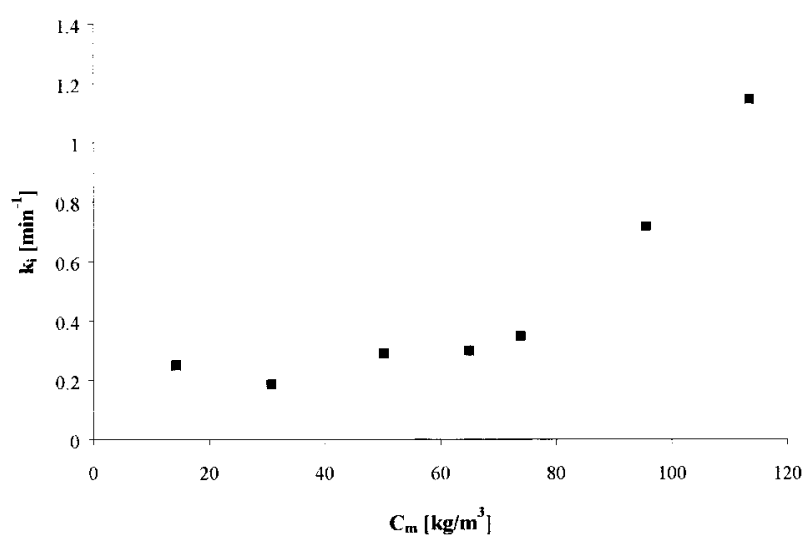

Figure 8. Influence of monomer concentration on $k_{i}$.

$(0-5.5 \mathrm{~mol} \%)$. The hydrogen concentration is calculated as the concentration in the gas phase because sorption data of hydrogen in a polymer swollen with monomer is not available. The influence of hydrogen on the kinetic constant $k_{p} C_{0}$ is given, showing a strong increase at low hydrogen concentration (Figure 9). At high hydrogen concentrations the slope decreases. Samson et al. ${ }^{18}$ also found a decreasing slope with increasing hydrogen concentration. Several possible explanations can be given for increasing polymerization rates at higher hydrogen concentrations. ${ }^{19}$

First, hydrogen may react with the surface of the heterogeneous catalyst to increase the number of active sites. Second, hydrogen may reactivate deactivated sites, which have been deactivated by components like metalallylics. Third, hydrogen may prevent the forming of unsaturated chain-end groups, which may act as a poison. However, the most plausible explanation is that hydrogen prevents the formation of dormant sites, which occur after a secondary insertion. ${ }^{18}$

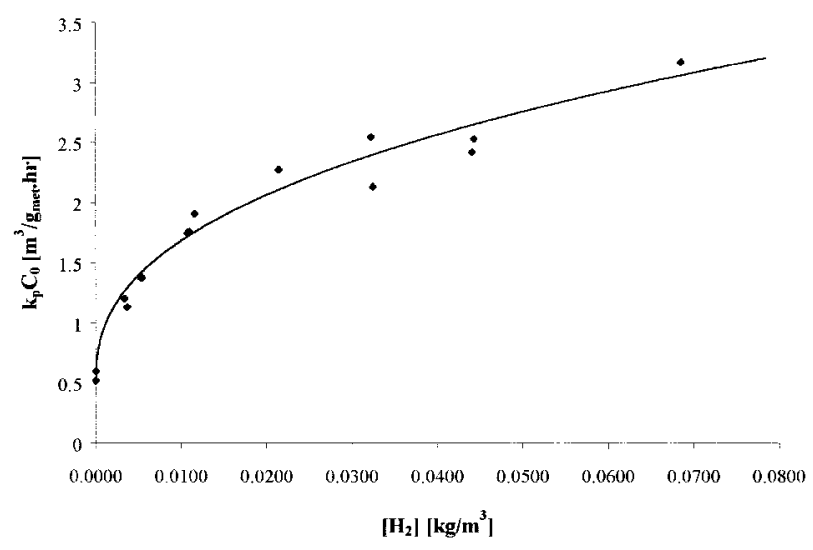

Figure 9. Influence of hydrogen on $k_{p} C_{0}$.

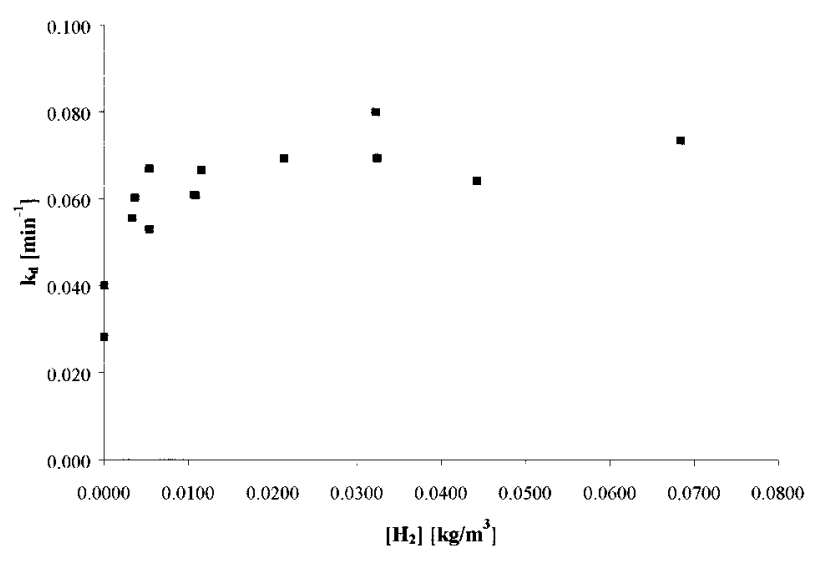

Figure 10. Influence of hydrogen on $k_{d}$.

The explanation for the decreasing slope at higher hydrogen concentrations can also be explained by several theories. First, at higher hydrogen concentrations the concentration of dormant sites will decrease causing a reduced reactivation effect of hydrogen. Second, the preceding temperature and pressure series support the theory of a runaway on particle scale above a critical polymerization rate. Values for the maximum polymerization activity are presented in Table III. These values are in the same order of magnitude, in case of high hydrogen concentrations, compared to the values obtained in the temperature and pressure series.

The given possible explanations do not exclude each other, but they might occur simultaneously.

The influence of hydrogen on the deactivation and activation constants is given in Figures 10 and 11 . The deactivation rate in the absence of hydrogen is substantially lower compared to higher hydrogen concentrations. The activation

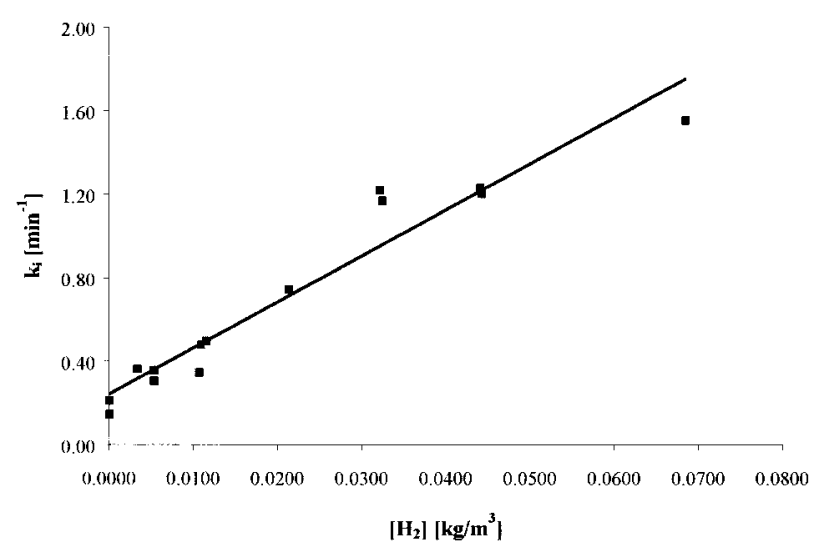

Figure 11. Influence of hydrogen on $k_{i}$. 


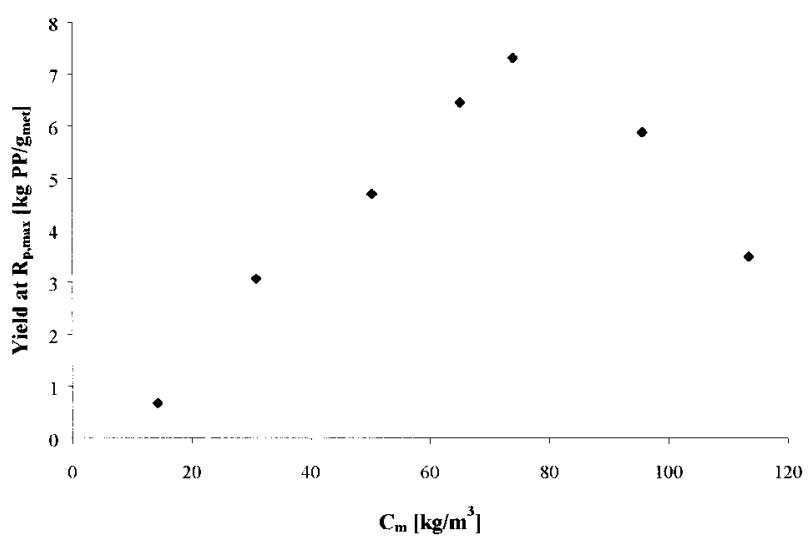

Figure 12. Influence of monomer concentration on the yield obtained after the maximum polymerization activity has been reached.

constant seems to be linearly dependent on the hydrogen concentration.

\section{Interpretation of the Acceleration Period}

As discussed earlier, several explanations for the initial acceleration period have been proposed in the literature. The particle growth model proposed by Bonini et al., ${ }^{10}$ assuming a shell-by-shell fragmentation from outside, is based on a diffusion-limitation process. According to this theory, the yield obtained at the point of maximum polymerization activity should be the same for every experiment, assuming little chemical deactivation processes in the acceleration period. Following our model, the yield at the moment of maximum polymerization activity can be determined by the surface below the rate-time curves in the following:

$$
\begin{aligned}
\text { Yield }= & \int_{0}^{t} k_{p} C_{0} C_{m} \frac{k_{i}}{k_{d}-k_{i}}\left(e^{-k_{i} t}-e^{-k_{d} t}\right) d t \\
= & k_{p} C_{0} C_{m} \frac{k_{i}}{k_{d}-k_{i}} \\
& \left\{\left[\frac{1}{k_{i}}\left(1-e^{-k_{i} t}\right)-\frac{1}{k_{d}}\left(1-e^{-k_{d} t}\right)\right]\right\}
\end{aligned}
$$

The calculated yield at the moment of maximum polymerization activity is given for the pressure series in Figure 12. As can be seen, the yield at maximum polymerization activity is certainly not the same for every experiment. Therefore, we interpret the increasing polymerization rate during the initial period as a physical and chemical process where several components, for example, metallocene, MAO, and TIBA, react to form the active species. The physical process is highly related to the particle morphology, which in turn is predefined in the early (fragmentation) stage of polymerization. Catalyst fragmentation depends mainly on two factors: hydraulic pressure generated by the polymer produced and rigidity of the support (see Weickert et al. $^{20}$ ). A fast increase of the hydraulic pressure, that is, high initial polymerization rates, leads to a large number of fragments, whereas low initial rates correspond to a small number of fragments. We have chosen to describe the initial acceleration period with an empirical model because the mechanism seems to be very complex.

\section{Molecular Weight and Molecular Weight Distribution}

The results from the GPC measurements $\left(M_{w}\right.$, $M_{n}$, and $\left.M_{w} / M_{n}\right)$ are presented for some of the samples produced during the kinetic studies at different process conditions (Table VI). The low molecular weight of the polymer is in agreement with results from the literature. ${ }^{10,19,21}$ In general, a narrow molecular weight distribution is obtained during polymerization with homogeneous metallocene catalysts at constant temperature and gas composition $\left(M_{w} / M_{n} \approx 2\right)$. Higher polydispersities are observed after polymerization with the heterogeneous analogues. ${ }^{10,22}$ The samples produced during the previously described kinetic measurements show polydispersities of around 2.5. One can calculate the chain-termination probability $q$ in two different ways, either based on $M_{n}$ or based on $M_{w}$, resulting in the same value if $M_{w} / M_{n}=2$ (see eq 10). The chaintermination probabilities based on $M_{n}$ and $M_{w}$ of the hydrogen series have been plotted against the relative hydrogen concentration $\left(C_{\mathrm{H} 2} / C_{m}\right)$, theoretically giving a straight line (see eq 9) (Fig. 13). Because $M_{w} / M_{n}>2$, the two lines in Figure 13 do not coincide. Moreover, at high relative hydrogen concentrations both kinds of chain-termination probabilities are smaller than expected.

Several possible explanations can be given for this behavior. First, the error made during the GPC analyses may increase with decreasing molecular weight. Second, a possible runaway on particle scale, as argued before, results in over- 
Table VI. GPC Data

\begin{tabular}{|c|c|c|c|c|c|c|c|}
\hline $\begin{array}{c}T \\
\left({ }^{\circ} \mathrm{C}\right)\end{array}$ & $\begin{array}{c}p \\
\text { (bar) }\end{array}$ & $\begin{array}{c}C_{\mathrm{H}_{2}} / C_{m} \\
(-)\end{array}$ & $\begin{array}{c}M_{n} \\
(\mathrm{~kg} / \mathrm{mol})\end{array}$ & $\begin{array}{c}M_{w} \\
(\mathrm{~kg} / \mathrm{mol})\end{array}$ & $\begin{array}{c}M_{w} / M_{n} \\
\quad(-)\end{array}$ & $q\left(M_{n}\right)(-)$ & $q\left(M_{w}\right)(-)$ \\
\hline 50 & 15 & $1.19 \cdot 10^{-4}$ & 11 & 25 & 2.3 & $3.82 \cdot 10^{-3}$ & $3.36 \cdot 10^{-3}$ \\
\hline 60 & 15 & $1.64 \cdot 10^{-4}$ & 8.6 & 23 & 2.7 & $4.88 \cdot 10^{-3}$ & $3.65 \cdot 10^{-3}$ \\
\hline 70 & 15 & $2.21 \cdot 10^{-4}$ & 8.1 & 19 & 2.3 & $5.19 \cdot 10^{-3}$ & $4.42 \cdot 10^{-3}$ \\
\hline 75 & 15 & $2.50 \cdot 10^{-4}$ & 6.9 & 17 & 2.5 & $6.09 \cdot 10^{-3}$ & $4.94 \cdot 10^{-3}$ \\
\hline 80 & 15 & $2.88 \cdot 10^{-4}$ & 7 & 17 & 2.4 & $6.00 \cdot 10^{-3}$ & $4.94 \cdot 10^{-3}$ \\
\hline 50 & 15 & 0 & 13 & 34 & 2.6 & $3.23 \cdot 10^{-3}$ & $2.47 \cdot 10^{-3}$ \\
\hline 60 & 15 & 0 & 14 & 31 & 2.2 & $3.00 \cdot 10^{-3}$ & $2.71 \cdot 10^{-3}$ \\
\hline 80 & 15 & 0 & 9.8 & 24 & 2.4 & $4.29 \cdot 10^{-3}$ & $3.50 \cdot 10^{-3}$ \\
\hline 70 & 5.1 & $7.75 \cdot 10^{-4}$ & 3.4 & 7.3 & 2.2 & $1.24 \cdot 10^{-2}$ & $1.15 \cdot 10^{-2}$ \\
\hline 70 & 14.8 & $2.21 \cdot 10^{-4}$ & 8.7 & 17 & 2.0 & $4.83 \cdot 10^{-3}$ & $4.94 \cdot 10^{-3}$ \\
\hline 70 & 17.9 & $1.69 \cdot 10^{-4}$ & 10 & 20 & 2.0 & $4.20 \cdot 10^{-3}$ & $4.20 \cdot 10^{-3}$ \\
\hline 70 & 19.5 & $1.49 \cdot 10^{-4}$ & 10 & 21 & 2.1 & $4.20 \cdot 10^{-3}$ & $4.00 \cdot 10^{-3}$ \\
\hline 70 & 22.6 & $1.15 \cdot 10^{-4}$ & 11 & 24 & 2.2 & $3.82 \cdot 10^{-3}$ & $3.50 \cdot 10^{-3}$ \\
\hline 70 & 15 & 0 & 12 & 27 & 2.3 & $3.50 \cdot 10^{-3}$ & $3.11 \cdot 10^{-3}$ \\
\hline 70 & 15 & $7.34 \cdot 10^{-5}$ & 9.6 & 22 & 2.3 & $4.38 \cdot 10^{-3}$ & $3.82 \cdot 10^{-3}$ \\
\hline 70 & 15 & $1.05 \cdot 10^{-4}$ & 8.3 & 20 & 2.4 & $5.06 \cdot 10^{-3}$ & $4.20 \cdot 10^{-3}$ \\
\hline 70 & 15 & $2.18 \cdot 10^{-4}$ & 7.3 & 17 & 2.3 & $5.75 \cdot 10^{-3}$ & $4.94 \cdot 10^{-3}$ \\
\hline 70 & 15 & $4.34 \cdot 10^{-4}$ & 5.4 & 13 & 2.4 & $7.78 \cdot 10^{-3}$ & $6.46 \cdot 10^{-3}$ \\
\hline 70 & 15 & $9.05 \cdot 10^{-4}$ & 3.9 & 10 & 2.6 & $1.08 \cdot 10^{-2}$ & $8.40 \cdot 10^{-3}$ \\
\hline 70 & 15 & $1.48 \cdot 10^{-3}$ & 3.3 & 8.1 & 2.5 & $1.27 \cdot 10^{-2}$ & $1.04 \cdot 10^{-2}$ \\
\hline
\end{tabular}

heating of particles during the start of the reaction. However, a relatively low amount of lower molecular weight polymer will be produced in this period. Degradation reactions of MAO or other co-catalyst compounds at higher temperatures may also lead to the forming of chain- termination agents.

Variation of the reaction temperature and pressure will also lead to a variation of the rela-

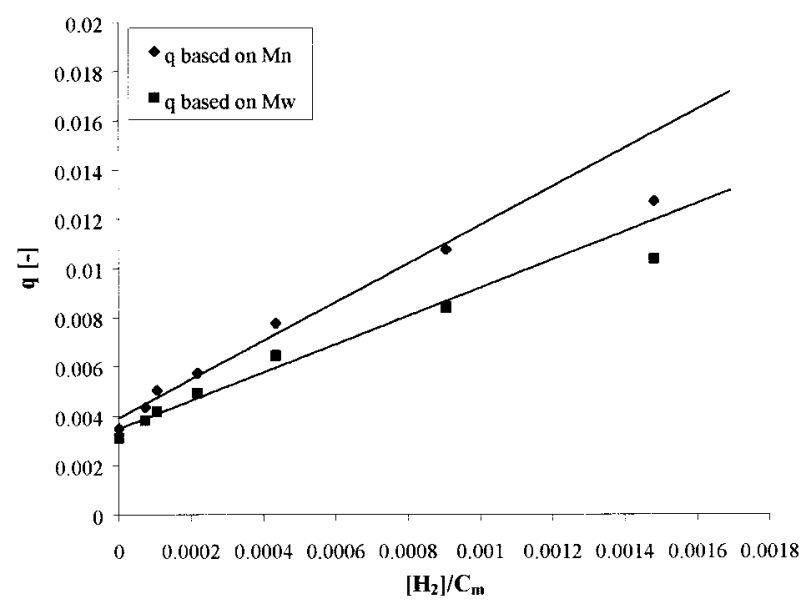

Figure 13. Influence of the relative hydrogen concentration on the chain- termination probability: samples from the hydrogen series. tive hydrogen concentration because of the changing monomer concentration in the polymer. The chain-termination probability based on $M_{w}$ of all kinetic series (temperature, pressure, and hydrogen) are given as functions of the relative hydrogen concentration in Figure 14. It can be seen that the dependency on temperature is not as strong as on the relative hydrogen concentration. This phenomenon is characteristic for the used catalyst and not generally valid. Phillips catalysts

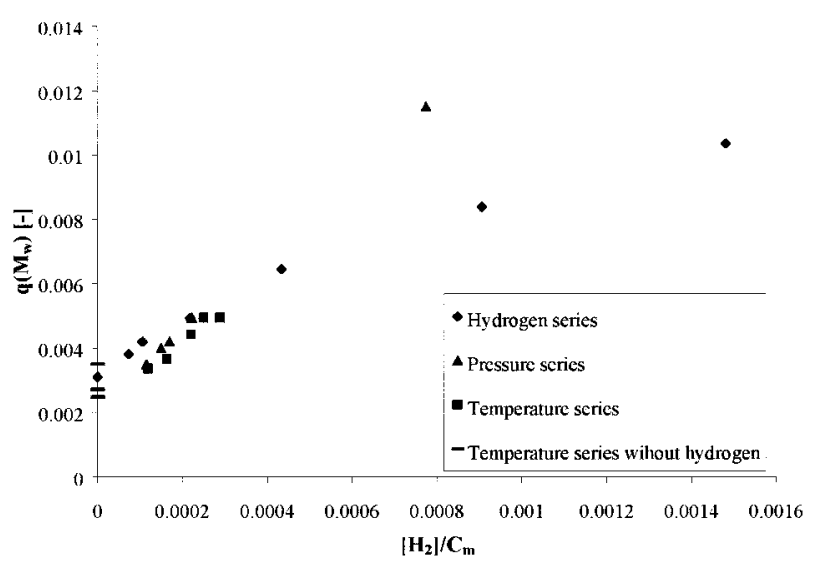

Figure 14. Influence of the relative hydrogen concentration on the chain- termination probability: samples from the all series. 


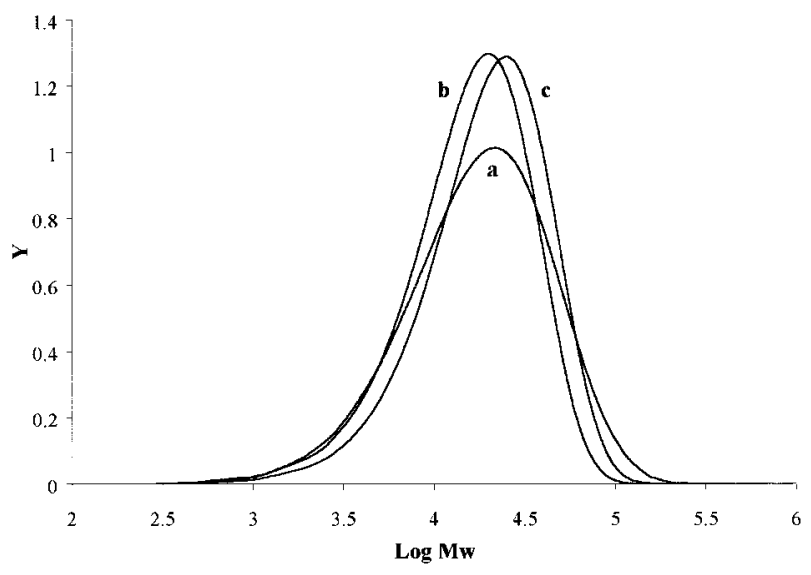

Figure 15. Simulation of the molecular weight distribution with Schulz-Flory distributions: (a) result from GPC analyses, (b) based on chain- termination probability calculated with $M_{n}$, and (c) based on chain-termination probability calculated with $M_{w}$.

$\mathrm{CrO} / \mathrm{SiO}_{2}$ are, for instance, hardly affected by hydrogen but are strongly dependent on temperature. $^{22}$

An example of the result is given from a GPC measurement together with two curves based on a Schulz-Flory distribution of $q$ values determined from $M_{n}$ and $M_{w}$ (Fig. 15). The GPC curve is broader, which is expected because of the higher polydispersity. Fait et al. ${ }^{17}$ postulated a kinetic model for a single-center, two-state catalyst. The two states differ in either their monomer insertion or coordination rate, thus having two different propagation rate constants. Different chemical possibilities for the nature of the two stated were discussed. The ratio between the two states depends, among others, on the monomer concentration. We observed first-order reaction kinetics at pressures above 15 bar, but neverthe-

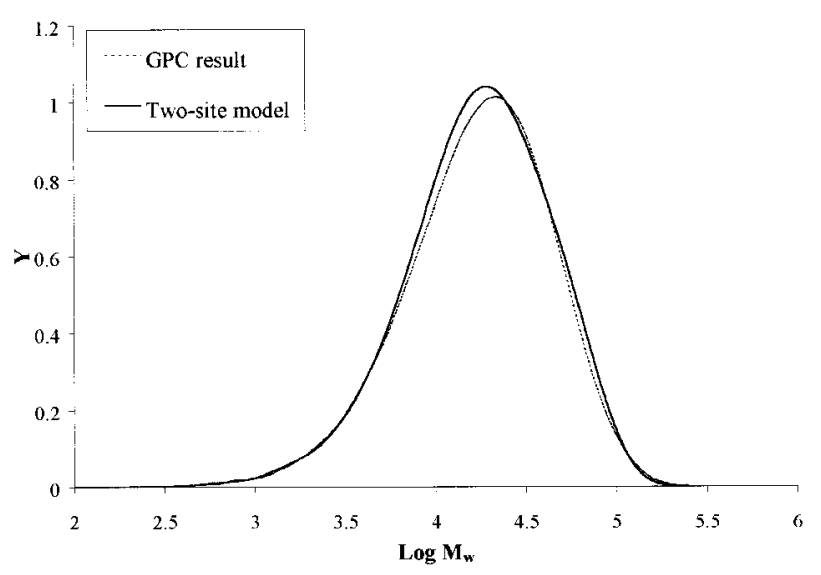

Figure 16. Simulation of the molecular weight distribution with the two-site model.

less observed non-single-site behavior. This may be related to the fact that our catalyst is supported, allowing for interaction of active sites and the support.

To obtain a better description of the molecular weight distribution, a "two-site model" has been used. The distributions obtained from the hydrogen series have been used to fit each distribution with two Schulz-Flory distributions assuming an equal polymerization rate of each site (50/50). An example of such a fit is given, presenting a much better fit as was obtained by using a single-site model (Fig. 16). The determined values for the chain-termination probability of both sites together with the errors of the model predictions are given in Table VII.

To check the assumption of equal productivity of each site, fitting has been repeated assuming a productivity ratio of sites 1 and 2 of 10/90 and 90/10, respectively. The obtained values for the chain termination probability of sites 1 and 2 for

Table VII. Chain-Transfer Probabilities for Sites 1 and 2, Assuming an Equal Productivity for Both Sites (50/50)

\begin{tabular}{lccc}
\hline $\begin{array}{c}C_{\mathrm{H}_{2}} / C_{m} \\
(-)\end{array}$ & $q_{1}(-)$ & $q_{2}(-)$ & \multicolumn{1}{c}{$\sum_{i=1}^{N}\left(Y_{\mathrm{GPC}}-Y_{\text {model }}\right)_{i}^{2}$} \\
\hline 0 & $2.05 \cdot 10^{-3}$ & $4.95 \cdot 10^{-3}$ & $0.28 \cdot 10^{-3}$ \\
$7.34 \cdot 10^{-5}$ & $2.49 \cdot 10^{-3}$ & $5.91 \cdot 10^{-3}$ & $0.38 \cdot 10^{-3}$ \\
$1.05 \cdot 10^{-4}$ & $2.64 \cdot 10^{-3}$ & $6.90 \cdot 10^{-3}$ & $0.49 \cdot 10^{-3}$ \\
$2.18 \cdot 10^{-4}$ & $3.28 \cdot 10^{-3}$ & $8.07 \cdot 10^{-3}$ & $0.82 \cdot 10^{-3}$ \\
$4.34 \cdot 10^{-4}$ & $4.02 \cdot 10^{-3}$ & $1.18 \cdot 10^{-2}$ & $1.00 \cdot 10^{-3}$ \\
$9.05 \cdot 10^{-4}$ & $4.86 \cdot 10^{-3}$ & $1.79 \cdot 10^{-2}$ & $1.90 \cdot 10^{-3}$ \\
$1.48 \cdot 10^{-3}$ & $7.12 \cdot 10^{-3}$ & $2.61 \cdot 10^{-2}$ & $2.42 \cdot 10^{-3}$ \\
\hline
\end{tabular}


Table VIII. Chain-Transfer Probabilities for Sites 1 and 2, Assuming a Relative Productivity for Sites 1 and 2 of 10 and $90 \%$

\begin{tabular}{lccc}
\hline \multicolumn{1}{c}{$\begin{array}{c}C_{\mathrm{H}_{2}} / C_{m} \\
(-)\end{array}$} & $q_{1}(-)$ & $q_{2}(-)$ & \\
\hline 0 & $1.18 \cdot 10^{-3}$ & $3.77 \cdot 10^{-3}$ & $\frac{1}{N} \sum_{i=1}^{N}\left(Y_{\mathrm{GPC}}-Y_{\text {model }}\right)_{i}^{2}$ \\
$7.34 \cdot 10^{-5}$ & $1.40 \cdot 10^{-3}$ & $4.71 \cdot 10^{-3}$ & $4.18 \cdot 10^{-3}$ \\
$1.05 \cdot 10^{-4}$ & $1.32 \cdot 10^{-3}$ & $5.50 \cdot 10^{-3}$ & $6.55 \cdot 10^{-3}$ \\
$2.18 \cdot 10^{-4}$ & $1.73 \cdot 10^{-3}$ & $6.22 \cdot 10^{-3}$ & $10.0 \cdot 10^{-3}$ \\
$4.34 \cdot 10^{-4}$ & $2.07 \cdot 10^{-3}$ & $8.45 \cdot 10^{-2}$ & $7.10 \cdot 10^{-3}$ \\
$9.05 \cdot 10^{-4}$ & $2.36 \cdot 10^{-3}$ & $1.18 \cdot 10^{-2}$ & $8.35 \cdot 10^{-3}$ \\
$1.48 \cdot 10^{-3}$ & $3.20 \cdot 10^{-3}$ & $1.56 \cdot 10^{-2}$ & $12.8 \cdot 10^{-3}$ \\
\hline
\end{tabular}

these cases are given in Tables VIII and IX, respectively. It can be seen that the errors found for these cases are larger compared to the errors found for the case in which equal site productivity was assumed. However, the productivity ratio between the two sites has not been optimized. The obtained values for the chain-termination probability of sites 1 and 2 for all three cases are plotted versus the relative hydrogen concentration (Fig. 17). It appears that both sites show a linear relation in all three cases, although the errors for the 10/90 and 90/10 model are much larger. Obviously, the linearity found is not a sufficient criterion to select the correct productivity ratio of the two-site model. The relations for the 50/50 model are given in the following:

$$
\begin{array}{r}
q_{1}=3.195 \frac{C_{\mathrm{H}_{2}}}{C_{m}}+0.0023 \\
q_{2}=14.20 \frac{C_{\mathrm{H}_{2}}}{C_{m}}+0.0051
\end{array}
$$

\section{CONCLUSIONS}

Gas-phase polymerizations of propylene with a heterogeneous metallocene catalyst have been executed at different temperatures, pressures, and hydrogen concentrations. The experimentally measured reaction rate curves have been simulated with a model, which considers both the activation as well as the deactivation of the catalyst. It is argued that the clearly observed initial acceleration stage is due to chemical activation processes rather than a diffusion limitation process.

At relatively high polymerization rates, deviations have been found from the model, which is attributed to a thermal runaway on particle scale. At these reaction conditions, the particle temperature may well be over the bulk temperature resulting in decomposition of vital catalyst components. Prepolymerization at low pressure and temperature increased the reaction rates. However, at higher temperatures large deviations with the Arrhenius plot still exist even for a prepolymerization time of $7 \mathrm{~min}$. Obviously, there

Table IX. Chain-Transfer Probabilities for Sites 1 and 2, Assuming a Relative Productivity for Sites 1 and 2 of 90 and 10\%

\begin{tabular}{lccc}
\hline \multicolumn{1}{c}{$\begin{array}{c}C_{\mathrm{H}_{2}} / C_{m} \\
(-)\end{array}$} & $q_{1}(-)$ & $q_{2}(-)$ & $\frac{1}{N} \sum_{i=1}^{N}\left(Y_{\mathrm{GPC}}-Y_{\text {model }}\right)_{i}^{2}$ \\
\hline 0 & $2.90 \cdot 10^{-3}$ & $9.00 \cdot 10^{-3}$ & $2.52 \cdot 10^{-3}$ \\
$7.34 \cdot 10^{-5}$ & $3.54 \cdot 10^{-3}$ & $1.20 \cdot 10^{-2}$ & $2.86 \cdot 10^{-3}$ \\
$1.05 \cdot 10^{-4}$ & $3.87 \cdot 10^{-3}$ & $1.47 \cdot 10^{-2}$ & $4.11 \cdot 10^{-3}$ \\
$2.18 \cdot 10^{-4}$ & $4.58 \cdot 10^{-3}$ & $1.65 \cdot 10^{-2}$ & $4.45 \cdot 10^{-3}$ \\
$4.34 \cdot 10^{-4}$ & $5.97 \cdot 10^{-3}$ & $2.45 \cdot 10^{-2}$ & $8.00 \cdot 10^{-3}$ \\
$9.05 \cdot 10^{-4}$ & $7.73 \cdot 10^{-3}$ & $3.91 \cdot 10^{-2}$ & $13.5 \cdot 10^{-3}$ \\
$1.48 \cdot 10^{-3}$ & $9.57 \cdot 10^{-3}$ & $5.23 \cdot 10^{-2}$ & $18.1 \cdot 10^{-3}$ \\
\hline
\end{tabular}




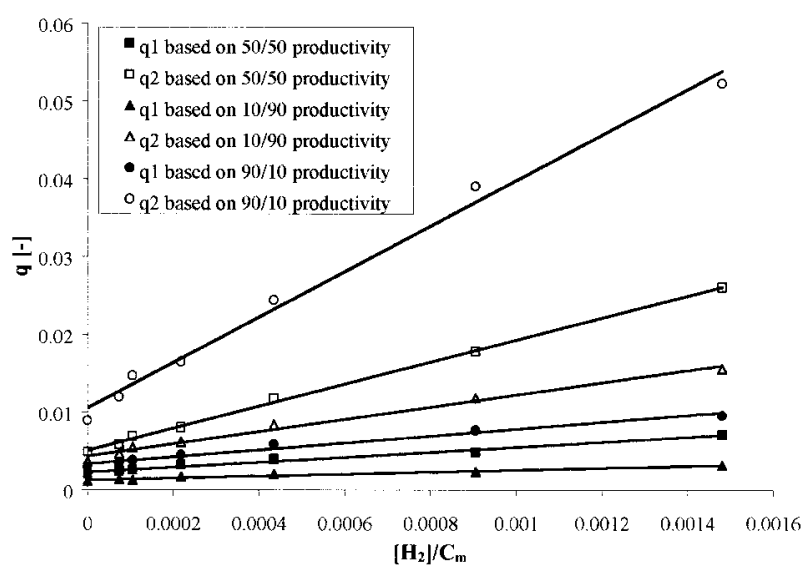

Figure 17. Determined chain-termination probabilities for sites 1 and 2 versus the relative hydrogen concentration.

are more effects to consider than only particle overheating.

For temperatures between 50 and $70{ }^{\circ} \mathrm{C}$, an activation energy for propagation was found to be $43.9 \mathrm{~kJ} / \mathrm{mol}$. This value is close to the value found by Meier et al., ${ }^{9} 48.0 \mathrm{~kJ} / \mathrm{mol}$, where the same metallocene was used on a similar support with a smaller average particle size for gas-phase polymerizations at 10 bar pressure. It is also important to mention that the same monomer sorption data has been used in the present article to allow comparison of these kinetic data. A higher activation energy has been found for polymerizations in the absence of hydrogen at 15 bar pressure: 58.9 $\mathrm{kJ} / \mathrm{mol}$.

The influence of monomer concentration has been investigated at pressures up to 25 bar. Again, deviations at high polymerization rates have been found, supporting the theory of a runaway at particle scale. The deactivation and activation constants are hardly affected by the monomer concentration for the range in which experiments have been done.

The influence of hydrogen on the polymerization kinetics has been investigated at concentrations between 0 and $5.5 \mathrm{~mol} \%$. At low concentrations, the reaction rate strongly increases, whereas this behavior flattens off at high concentrations. The most plausible explanation for the increased activity with increasing hydrogen concentration is the reactivation of dormant sites by hydrogen.

The molecular weight and molecular weight distribution of the polymer samples produced during the kinetic study have been analyzed by
GPC. The low molecular weight of the polymer is characteristic for the applied catalyst system. The molecular weight distribution is broader than expected for a single-site catalyst, but in agreement with the results reported for heterogeneous metallocene catalysts. The results from the temperature series are reasonably consistent with the results from the hydrogen and pressure series when the chain-termination probability is plotted versus the relative hydrogen concentration. An empirical "two-site model" has been used to provide a better description of the molecular weight distribution. Two Schulz-Flory distributions have been used to fit the observed distribution assuming an equal productivity of each site. Variation of the productivity ratio leads to larger errors between the model and GPC curves. The determined chain-termination probabilities for each site are found to be linearly dependent on the relative hydrogen concentration, independent of the productivity ratio. The linearity itself is obviously not a sufficient criterion to select the correct productivity ratio of the two-site model.

This work has been funded by BRITE-EURAM Project CATAPOL (BE 96-3022). The authors further wish to thank DSM Research for the GPC measurements.

\section{NOMENCLATURE}

C Number of potential active sites $\left(\mathrm{mol} / \mathrm{g}_{\mathrm{met}}\right)$

$C^{*} \quad$ Number of active sites $\left(\mathrm{mol} / \mathrm{g}_{\mathrm{met}}\right)$

$C_{\mathrm{H} 2}$ Hydrogen concentration $\left(\mathrm{kg} / \mathrm{m}^{3}\right)$

$C_{m} \quad$ Monomer concentration $\left(\mathrm{kg} / \mathrm{m}^{3}\right)$

$E_{\text {act }}$ Activation energy (J/mol)

$j \quad$ Chain length

$k_{d} \quad$ Deactivation rate constant $\left(\mathrm{min}^{-1}\right)$

$k_{\mathrm{H} 2}$ Chain-transfer constant for hydrogen $\left(\mathrm{m}^{3} /\right.$ molih)

$k_{i} \quad$ Activation rate constant $\left(\mathrm{min}^{-1}\right)$

$k_{m}$ Chain-transfer constant for monomer $\left(\mathrm{m}^{3} /\right.$ molih)

$k_{p} \quad$ Propagation rate constant $\left(\mathrm{m}^{3} / \mathrm{molh}\right)$

$k_{x} \quad$ Chain-transfer constant (other than $\mathrm{H}_{2}$ and m) $\left(\mathrm{m}^{3} / \mathrm{molh}\right)$

$M_{m} \quad$ Molecular weight of the monomer $(\mathrm{kg} / \mathrm{mol})$

$M_{n} \quad$ Number-averaged molecular weight (kg/ mol)

$M_{w} \quad$ Weight-averaged molecular weight $(\mathrm{kg} / \mathrm{mol})$

$p \quad$ Pressure (bar)

$q \quad$ Chain-termination probability

$R \quad$ Gas constant (J/molK)

$R_{p} \quad$ Reaction rate $\left(\mathrm{kg} / \mathrm{g}_{\text {met }} \dot{\mathrm{h}}\right)$ 
$T \quad$ Temperature (K)

$t \quad$ Time (min)

$Y \quad$ Standard format for GPC curve: $y_{j}^{d} M_{m} j(\mathrm{~kg} /$ mol)

$y_{j}^{d} \quad$ Density function of the instantaneous molecular weight distribution

\section{Greek}

$\chi \quad$ Flory-Huggins interaction parameter

\section{Subscripts}

0 Initial value

1 Site 1

2 Site 2

d Deactivation

$i$ Activation

$p$ Propagation

\section{Abbreviations}

GPC Gel permeation chromatography

MAO Methylaluminoxane

TIBA Tri-isobuthylaluminium

\section{REFERENCES AND NOTES}

1. Roos, P.; Meier, G. B.; Samson, J. J. C.; Weickert, G.; Westerterp, K. R. Macromol Rapid Commun 1997, 18, 319-324.

2. Samson, J. J. C.; van Middelkoop, B.; Weickert, G.; Westerterp, K. R. AIChE J 1999, 45(7), 1548-1558.

3. Resconi, L.; Fait, A.; Piemontesi, F.; Colonnesi, M.; Rychlicki, H.; Zeigler, R. Macromolecules 1995, 28, 6667-6676.
4. Janiak, J.; Rieger, B. Angew Makromol Chem 1994, 215, 47-57.

5. Fischer, D.; Muelhaupt, R. J Organomet Chem 1991, 417, C4-C11.

6. Fischer, D.; Juengling, S.; Muelhaupt, R. Makromol Chem Macromol Symp 1993, 66, 191-202.

7. Kitagawa, T.; Uozumi, T.; Soga, K.; Takata, T. Polymer 1997, 38(3), 615-620.

8. Michelotti, M.; Altomare, A.; Ciardelli, F.; Roland, E. J Mol Catal A 1998, 129, 241-248.

9. Meier, G. B.; Weickert, G.; van Swaaij, W. P. M. J Appl Polym Sci, in press, 2000.

10. Bonini, F.; Fraaije, V.; Fink, G. J Polym Sci Polym Chem Ed 1995, 33, 2393-2402.

11. Kim, I.; Choi, H. K.; Kim, J. H.; Woo, S. I. J Polym Sci Polym Chem Ed 1994, 32, 971-977.

12. Wester, T. S.; Johnsen, H.; Kittelsen, P.; Rytter, E. Macromol Chem Phys 1998, 199, 1989-2004.

13. Weickert, G. Modellierung von polymerisationsreaktoren; Springer-Verlag: Berlin, 1997; Chapter $3, \mathrm{p} 37$.

14. Floyd, S.; Choi, K. Y.; Taylor, T. W.; Ray, W. H. J Appl Polym Sci 1986, 31, 2231-2265.

15. Floyd, S.; Choi, K. Y.; Taylor, T. W.; Ray, W. H. J Appl Polym Sci 1986, 32, 2935-2960.

16. McKenna, T. F.; Spitz, R.; Cokljat, D. AIChE J 1999, 45(11), 2392-2410.

17. Fait, A.; Resconi, L.; Guerra, G.; Corradini, P. Macromolecules 1999, 32, 2104-2109.

18. Samson, J. J. C.; Bosman, P. J.; Weickert, G.; Westerterp, K. R. J Polym Sci Polym Chem Ed 1999, 37(2), 219-232.

19. Carvill, A.; Tritto, I.; Locatelli, P.; Sacchi, M. C. Macromolecules 1997, 30, 7056-7062.

20. Weickert, G.; Meier, G. B.; Pater, J. T. M.; Westerterp, K. R. Chem Eng Sci 1999, 54, 3291-3296.

21. Spaleck, W.; Aulbach, M.; Bachmann, B.; Kuüber, F.; Winter, A. Macromol Symp 1995, 89, 237-247.

22. Blom, R.; Dahl, I. M. Macromol Chem Phys 1999, $200,442-449$. 